\title{
Moving beyond Smart Cities: Digital Nations for Social Innovation \& Sustainability
}

\author{
Arpan Kumar Kar ${ }^{1}$ - Vigneswara llavarasan ${ }^{1}$ - M. P. Gupta ${ }^{1}$ - Marijn Janssen ${ }^{2} \cdot$ Ravi Kothari $^{3}$
}

Published online: 31 May 2019

(C) Springer Science+Business Media, LLC, part of Springer Nature 2019

\begin{abstract}
The next step after smart cities is the creation of digital or smart nations. A digital nation requires a national transformation across diverse institutions including the urban and rural areas of a society. Besides diverse social innovation initiatives, sustainability is a key aspect, so that rather than greenfield projects, long-term solutions will involve brownfield, smart city projects. A digital transformation to a digital or smart nation requires a great deal of innovation in planning, process re-engineering and execution. Whereas research work and policy actions are traditionally focused on a city level, these efforts need to be widened to the national level. Existing city-scale theories and frameworks may be used and adapted to meet the larger-scale needs of the future smart nations. The new issues and research challenges which arise need to be addressed through interdisciplinary approaches. This special issue on the theme of digital nations attempts to address the need in the academic literature to provide a better understanding of digital nations.
\end{abstract}

Keywords Digital nations - Smart nations $\cdot$ Smart cities · Innovation $\cdot$ Sustainability $\cdot$ Information and communication technology $\cdot$ Technology impact $\cdot$ Technology adoption $\cdot$ Implementation barriers

\section{Introduction}

Countries are moving from a digital transformation towards the realization of a digital nation. A digital nation can be defined as a country in which urban and rural citizens, governments, and businesses live in a digital society that interacts and generates value, which benefits all stakeholders. The concept of digital nations is broader and more encompassing than smart cities, as it covers an entire country.

Smart city initiatives are restricted to the scope of a city, and what constitutes a 'smart city' is ambiguous. Hollands already questioned this in his article 'Will the real smart city please stand up' (Hollands 2008). Smartness is also an illunderstood concept (Gil-Garcia et al. 2016), and smart city concepts have been criticized for being too technocratic, ignoring existing political realities and citizens.

\section{Marijn Janssen}

M.F.W.H.A.Janssen@tudelft.nl

Department of Management Studies, IIT Delhi, New Delhi, India

2 Delft University of Technology, Delft, Netherlands

3 Ashoka University, Sonipat, India
Furthermore, technology use has been viewed as a goal instead of a means - to make our cities clean and more sustainable. All too often an optimistic view of the potential of technology is taken without considering the possible risks and adverse effects. Smart cities practices also cannot be something that is added next to existing initiatives; the practices need to be embedded in all aspects of city governance. Smart cities also need smart citizens (Janssen et al. 2015).

Interpreting data can also be problematic. More data might not make people smarter and mistakes and bias can occur, not increasing the smartness of citizens. Data and their accompanying algorithms can 'systematically introduce inadvertent bias, reinforce historical discrimination, favor a political orientation or reinforce undesired practices' (Janssen and Kuk 2016 p. 371). Only smart people can see that this is happening.

At the far end, a smart city might be focused on gaining more control by monitoring its citizens using cameras. In this case, these interventions are often made by only a few people without being held accountable for their actions to the public. This action might actually make people less smart and less responsible as they become monitored. As such, a view is needed which takes into account a realistic view of technology embodied in a societal context, in which both influence each other. Instead, a digital and smart nation should take the societal needs as a starting point and the larger governance system 
responds to these needs. This view should also acknowledge that nations are different in various ways.

Digital nations can learn from the experiments conducted by smart cities. Growing population and urbanization needs are motivating national governments to develop smart cities and digital nations. The more considerable the population growth, the bigger the need to bridge the economic, social and digital divide with a focus on sustainability (Dwivedi et al. 2012). This has to be enabled through the use of emerging paradigms of Information and Communication Technologies (ICTs) like the Internet of Things (IoT), Artificial Intelligence (AI) and data-driven services (Chatterjee et al. 2018b). Additionally, the planning and implementation of smart cities are leveraging emerging technologies like IoT and cloud computing as the foundation to improve processes and outcomes in urbanization efforts (Liu and Peng 2014). However, these technologies can be used and also misused in various ways and need to be secured to avoid adverse impacts to the society (Chatfield and Reddick 2018). To gain the advantages of such emerging technologies, governments are also facilitating the interaction of citizens with such technologies (Chatterjee et al. 2018).

Different countries approach the smart challenge differently. For example, India and China have initiated the planning of more than 100 and 200 smart cities respectively. In the absence of a nationwide smart city framework and the diversity of needs across different cities, each city has developed its own data formats and systems. As a result, the systems are incompatible resulting in data islands that cannot be integrated across these cities. As countries like India and China have largely rural populations, the urban bias in smart city projects needs to be addressed to become more inclusive for making such projects sustainable for the national population. In countries like India and Bangladesh, however, the governments have taken up initiatives like 'Digital India' and 'Digital Bangladesh' to transform the government and governance using ICTs across the country. Similar initiatives have been undertaken in Europe and Australia. This digital transformation across the nation starts with simple digitisation initiatives, followed by digitalisation and subsequently matures into the digital transformation of the nation.

\section{From Smart Cities to Smart Nations}

Smart cities can be viewed as a middle step in the journey towards realising a digital nation. However, cities are diverse and need different types of smart city initiatives. Smart cities are urbanisation efforts undertaken at the city municipality level whereby many services for residents can utilise ICTs. One focus of such ICT usage would be to utilise emerging technologies like IoT and AI to minimise human intervention in processing and decision-making (Kankanhalli et al. 2019).
This focus creates information assets gathered from various sources like cyber-physical systems.

These information assets must be managed efficiently and innovatively to enable the city administration to be more effective. For example, the usage of smart devices in different public domains like parking places, electricity grids, and streetlight lights, etc. results in data capturing. This data has a high volume, velocity, veracity and variety, which if managed effectively can generate immense value to both the city administration and citizens. To harness this value, governments are trying to operate smartly by collecting, collating, categorizing, analyzing, interpreting and distributing the insights from the data in public service delivery.

However, there is more to smart cities than the scope of ICTs and data. For example, the data-driven approach helps cities to implement functionalities like smart mobility by providing safe, fast and efficient routes using traffic data. The approach also enables smart living by providing comfort and convenience using data from IoT home products and systems. But there is also a need to protect the future needs of the society and accomplish societal values like transparency (Matheus et al. 2018). Also, the planning for the social architecture needs to cater to inclusiveness from the perspectives of digital, social, economic, professional and personal development. These five development targets need to be achieved without compromising the needs of the future in a sustainable approach.

An extension of the digital transformation of smart cities to a national level is the process of creating digital nations. In smart cities, the urban transformation happens at the city level, and often such efforts are localised. At a very basic level, a digital nation is more of a connected nation that can share information and intelligence dynamically, in real time to deliver services and improve the quality of life of its citizens. This requires an integrated infrastructure in which data sources and software functionality are shared. However, such development is likely to restrict its scope within urban and semi-urban pockets of the nation. To gain collective efficiencies and dissipate the pressure of economic, social and community expectations from the smart cities alone, evolution towards digital nations seems indispensable. This may even require a structural transformation and a different way of governing projects. Digital nations consist of a dense network of smart cities which have achieved five inclusive development goals: the development of its residents' digital, social, economic, professional and personal needs with significant spillover effects beyond the urban and semi-urban areas.

As the global economy is interconnected, the government of such digital nations needs to take initiatives to move beyond smart cities to sustain the national economy even in adverse conditions. The nation as a whole should target selfsustainability as the cities are part of a larger network which fulfils a diverse set of needs for the nation. The rural areas are 
an important node in such a network; they complement the economy by not only servicing the needs of the urban population but also creating economic value through grassroot innovations and economic activities for all citizens, including those living in rural areas. Equitable access to information, and economic, social and commercial resources, need to be provided. The citizens also need to be acquainted with their rights and privileges and receive significant levels of empowerment - relational, cognitive, behavioral and psychological - in current and future digital nations. Some countries are moving in this direction. For example, the French government in partnership with Cisco has a digital development programme which provides French students with the opportunity to develop their skills and expertise in the field of networking, infrastructure and design (Villa 2015).

With the advancement and adoption of ICTs, the potential to move beyond smart cities to digital or smart nations is tremendous. However, guiding frameworks and institutional structures need to be enabled for this desired transformation. The study of digital nations requires interdisciplinary research methodologies, theories and lenses due to the high level of complexity arising out of the scope of research. A smart ecosystem needs to address both technological and management perspectives, and researchers are focusing on resolving this problem (Janssen and Helbig 2018). In the technology domain, researchers are also focusing on developing the ICTs, IoT, etc., so that they can improve the stability, flexibility, robustness, reliability, and sustainability of the smart cities and for the nation. At the same time in the management domain, researchers are focusing on issues related to governance and implementation of technology in the smart cities and nation, and technology-enabled transformation initiatives can help a nation achieve environmental sustainability (Chatterjee et al. 2018a). Smart city initiatives can also assist in identifying the causes of pollution, natural calamities, etc. Further, with Web 3.0 and social media, people and communities are interacting with each other to gain personal and professional information. In turn, governments are also communicating with their people via social initiatives like 'REACH' in Singapore, 'Mann Ki Baat' in India, 'MyGov' in Australia, etc. Using these social initiatives, governments are receiving input from different stakeholders and improving government services and utilities.

As the concept of digital nations is relatively new, previous research has largely been inadequate. However, ongoing research studies are contributing to the body of literature for realising digital nations. Some of the common characteristics of these studies include:

- viewing smart city initiatives as part of national level priorities;

- developing internet and telecommunications infrastructure to connect every citizen to the web;
- employing new technologies in all possible areas of service delivery, especially digital service delivery;

- with extensive usage of Information and Communication Technologies (ICTs) for improving the lives of citizens;

- with a focus on societal goals, like realising sustainability, better waste management and reducing pollution;

- utilising interdisciplinary approaches to study organisations and society to achieve national objectives.

This special issue aims to fill the gap in the existing literature on digital nations. Apart from examining problems related to the adoption and use of technologies, government policies, and social media adoption for public participation in digital nations, it also provides input for future digital nations.

\section{Digital Nations - A Framework}

The research paradigm on smart nations should have contributions from diverse theoretical blocks, multiple areas of research ranging from information risk to sharing economy, and integrate positivist and interpretative paradigms of research (see Fig. 1). The theoretical building blocks for developing this literature in digital nations can stem from classic information systems research theories like management theory, organization theory, behavioural theory, computer science theories and systems theory (Barki et al. 1993). These theories are likely to impact areas of research like public policy, data science, technology use, technology ecosystems, ambidexterity issues and innovation for the digital nation. The interdisciplinary approaches from these areas are likely to contribute to the existing literature on digital nations in areas like sustainability; partnerships; value co-creation; technology-driven solutions; technology-enabled processes; innovations in services, processes and business models; planning and implementation challenges; multi-dimensional impacts and its implications for the future.

As indicated in Fig. 1, building upon the theoretical blocks of information systems, we feel that the fundamental theoretical blocks for research may stem from management, behavioral, organisation, computer science, decision, and systems theories. However, since the speed of digital transformation has taken off, managing such new emerging technologies requires revisiting classic theories in information systems research, while the speed of progress necessitates revisiting, extending and adapting older theories. Questions beyond how such new generation information systems are developed, managed and consumed while interacting with individuals, groups, organizations, and markets may still be relevant, but the exploration requires an interdisciplinary approach more than ever, and one that integrates positivist and interpretive paradigms of research. In order to realise the full potential of smart cities and digital nations, plenty of 'out of the box' 
Stakeholders: Profit firms, Markets, Not for profit organizations, Citizens, Policy makers Unit of Analysis: Organisation, Groups, Government, Citizens

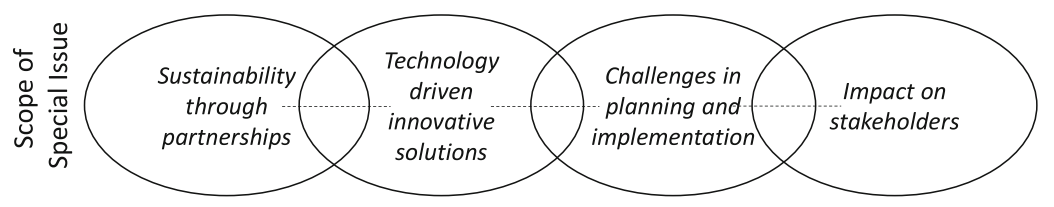

Research Methodology: Integration of positivist and interpretive paradigms of research

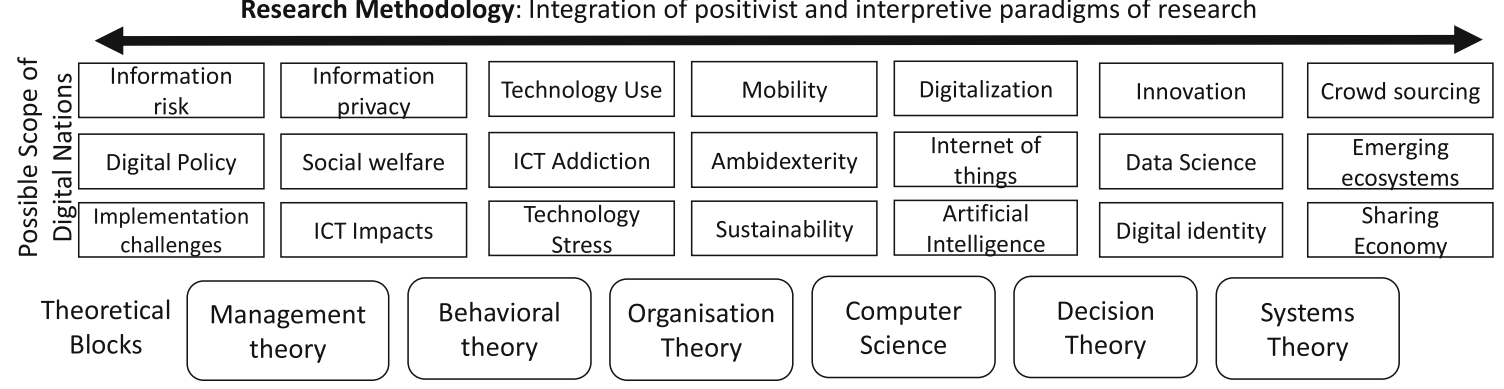

Fig. 1 A Conceptual Framework for Digital Nations - from building blocks to themes for theoretical contribution

theorising is required to learn more and provide new directions.

The emergence of new business models (e.g., sharing economy, crowdsourcing, etc.) enabled by new technology (artificial intelligence, data science, etc.) may create challenges for future generations which may require deep introspection and theorising. The blocks in Fig. 1 which highlight the possible focus of studies on digital nations are probably just the tip of the iceberg, as we venture towards the journey of realising such digital transformation at a national level. Such a realisation would often have some barriers, from the perspective of technology, policy, stakeholder support and organisational readiness. Further validation of such conceptual frameworks may need the adaptation of research methods that can interpret the new nature of data (velocity, volume, veracity, variety) that is created in this drive towards digital transformation. Approaches from machine learning and data science may need to be combined with traditional methods like statistical analysis and qualitative research methods to provide insights beyond traditional approaches in information systems research.

\section{Overview of Papers}

This special issue is an extension of the conference proceeding ' $16^{\text {th }}$ International Federation of Information Processing (IFIP) on e-Business, e-services and e-Society'. We have organized articles broadly cutting across four themes: challenges in planning and implementation, technology-driven innovations, creating sustainability through partnerships, and impact on stakeholders. Twenty-five articles were submitted out of which eight articles were selected for publication. The articles were chosen based on a double-blind peer review process and subsequently two to three rounds of revisions based on the reviews. The published authors are from Australia, China,
Estonia, Finland, France, India, Portugal, Qatar, South Africa, Spain, and the United Kingdom. Overall, the articles utilise various theoretical approaches, and empirical results emerge from a wide range of qualitative and quantitative research methodologies. This research considers different facts and scenarios, shows case-based research, and presents literature reviews related to the domain of smart cities and digital nations.

\subsection{Challenges in Planning and Implementation}

Smart cities inherit a wide variety of technical, managerial and governance challenges - on one platform. Therefore, when transforming a city into a smart city, an immense amount of planning and strategic execution is required.

Two papers in this issue address this topic. First, in 'Identifying and Prioritizing Barriers to the Development of Smart Cities in Indian Context', Rana et al. have identified 31 key barriers to the development of smart cities. These barriers have been further categorized into six dimensions: 'Governance, Economic, Technology, Social, Environmental and Legal \& Ethical'. For their study, they have utilised Fuzzy Analytic Hierarchy Process (AHP) based decision-making to determine the biggest critical barriers to the development of smart cities. This is followed by sensitivity analysis to determine a more precise and stable ranking of these barriers. To verify their findings, data from experts that are working on smart cities project in India has been utilised. Rana et al. have found that out of the six categories, governance-related barriers like coordination issues within the city's operational network, not having a clear goal for IT management, political instability, etc., are the most significant hurdles in India.

Second, Rahman et al. (2019) investigate various technical challenges during innovation processes while using smart digital technologies in the smartphone industry in 'Value Co- 
creation as a Dialectical Process: Study in Bangladesh and India Province of West Bengal'. They show multiple stakeholder engagement in value co-creation within the firm. For their research, they conducted in-depth interviews of 28 respondents for an average of 30-45 $\mathrm{min}$. The qualitative data has been analysed, and their findings demonstrate that technological innovation through stakeholders has impact on coinnovation, co-production - and sometime co-destruction, which together constitute the factors driving value cocreation.

\subsection{Technology-Driven Innovations}

Technology plays a vital role in smart cities, and innovative technological strategies efficiently help cities become smart. Such innovations often cannot be restricted at a process level and a change in the overall model of operations is often required. Sometimes innovative solutions reduce time and effort by government and the plan is executed safely.

Two technology-driven solutions that can help government implement smart cities are discussed in this issue. First, in 'Leveraging Smart Supply Chain and Information System Agility for Supply Chain Flexibility', Gupta et al. (2019b) have employed organization information processing theory to achieve greater flexibility in the supply chain between customer and supplier. The data for this study has been collected through a survey on a Likert scale from 150 respondents working in South Africa. The authors used structured equation modelling for data analysis of the survey data. Their results suggest that, in comparison to the customer, suppliers have more effect on the relationship between information system agility and supply chain flexibility. A supply chain with information processing capabilities may hamper supply chain flexibility due to the delay caused by the centralised information processing system.

Second, Wang, Jin \& Mao (2019) propose a model based on individual as well as organisational technology adoption in their article "Farmer Cooperatives" Intention to Adopt Agricultural Information Technology-Mediating Effects of Attitudes.' They have integrated two widely used frameworks, the Technology Acceptance Model (TAM) and the Technology-Organisation-Environment framework (TOE), to formulate their model. They received data from 288 respondents through a questionnaire in China, and they utilised Confirmatory Factor Analysis (CFA) to check the validity and reliability of the proposed model. The results indicate that environmental factors play a more important role for the adoption of agricultural ICTs in comparison to the technological and cooperative focused factors.

\subsection{Creating Sustainability through Partnerships}

Countries, especially developing nations, may gain the most benefits from digital transformation. They have initiated smart cities pilot projects, which can become the basis for digital nation development. However, it is not possible for governments to push this agenda alone. By using ICTs, some countries are scaling innovative solutions across entire countries. They need to invest in advanced infrastructure and skills development programmes for their new generations while collaborating with stakeholders to make such efforts sustainable.

Two articles in this issue address these concerns. First, Akande et al. (2019) analyse the relationship between ICT development and the environmental sustainability of cities at the micro-level in the article 'Assessing the Gap between Technology and the Environment Sustainability of European Cities'. They have used principal component analysis and cluster analysis methods to group homogenous EU cities by ICT development and environmental sustainability. In this study, secondary data from 129 European cities related to identified variables (e-Bank, e-Health, email, e-Commerce, broadband, e-Learn) of ICT development and environmental sustainability are sourced from ITU, OECD, and Eurostat. The results suggest a gap between the two areas especially in cities located in south-eastern Europe. Second, in 'Design of an O2O Citizen Participation Ecosystem for Sustainable Governance', Ju, Liu \& Feng (2019) present a social exchange theory-based ecosystem which is more citizen-centric. They show how offline and online participation by citizens can improve governance. To check the propensity of the proposed model, they conducted a case study in the municipal government of Nanjing, China. Their results show that the conceptual ecosystem is more efficient with a design science research (DSR) approach. Ju, Liu \& Feng (2019) suggest that an O2O governance ecosystem can help government establish sustainable relationships with citizens strategically.

\subsection{Impact on Stakeholders (Organizations, Government, and Citizens)}

The citizen is possibly the most important stakeholder of the digital nation. Governments and organizations need to improve their services to citizens. Other stakeholders include technology manufacturers, application developers, service providers, and related organizations have the opportunity to nurture themselves and provide services for the betterment of digital nations through innovation and intellectual property creation. Some of the issues which may impact various stakeholders of digital nations are discussed in two articles in this issue.

First, Tammpuu \& Masso (2019) explore the level of penetration of a government digital infrastructure scheme and eservices in Estonia in 'Transnational Digital Identity as an Instrument for Global Digital Citizenship: The Case of Estonian E-residency'. They suggest that the individual choice of opting for a universal digital identity is affected by sociodemographic and macro-level characteristics. Data from 33,039 individual applicants collected by the Estonian Police 
and Border Guard are analysed for theory-testing purposes. Their findings support that the demographic is not the only reason for choosing e-residency by individuals; and other country-level factors like professional interests, business interests, education and cultural ecosystems and information security also play a role.

Second, Al-Muwil et al. (2019) have identified the crucial factors impacting e-government use and the intersection point between e-adoption and e-inclusion in 'Balancing Digital-bydefault with Inclusion: A Study of the Factors Influencing Einclusion in the UK.' For their analysis, they utilised a questionnaire of 510 respondents for data collection, followed by confirmatory factor analysis to measure the stability and reliability of the model. Statistical validation demonstrates that by influencing people to use e-government, the factor related to e-inclusion could be understood (Gupta et al. 2019a).

\section{Conclusions}

While smart cities focus on the scope of a city, smart nations take a broader perspective. They are aimed at connecting smart city initiatives and focus on nationwide innovation and sustainability. A digital or smart nation can provide its citizens better services, innovative solutions for resolving social problems and support citizens in being smart. Digital nation initiatives can be planned by taking and adapting the learning from the implementation of smart cities. Depending on whether such projects would be greenfield projects or brownfield projects, the literature on smart cities and case studies can offer tremendous insights for theory building and practice.

However, the issues and the development of digital nations solutions are still in a very early stage. This special issue addresses some of the challenges related to the development of smart nations and contributes to this developing literature and future research. Given the focus of organisations like the United Nations, advocating economic development, industrial growth and urbanisation without compromising sustainability, as indicated by sustainable development goals, digital nations have the prospect of contributing to even wider research, and having wider impact, in the future.

Acknowledgements We would like to thank all of the authors and reviewers for their constructive support and contributions to this special issue. Further, the support and advice from Prof. H.R. Rao, Editor-in-Chief, have been extremely helpful for us to take this special issue to this level.

\section{References}

Akande, A., Cabral, P., \& Casteleyn, S. (2019). Assessing the gap between technology and the environmental sustainability of European cities. Information Systems Frontiers, 21(3). https://doi.org/10. 1007/s10796-019-09903-3.
Al-Muwil, A., Weerakkody, V., El-Haddadeh, R., \& Dwivedi, Y. (2019). Balancing digital-by-default with E-inclusion: A study of the factors influencing E-inclusion in the UK. Information Systems Frontiers, 21(3). https://doi.org/10.1007/s10796-019-09914-0.

Barki, H., Rivard, S., \& Talbot, J. (1993). A keyword classification scheme for IS research literature: An update. MIS Quarterly, 17(2), 209-226.

Chatfield, A. T., \& Reddick, C. G. (2018). A framework for internet of things-enabled smart government: A case of IoT cybersecurity policies and use cases in US federal government. Government Information Quarterly, 26(2), 346-357.

Chatterjee, S., Kar, A. K., Dwivedi, Y. K., \& Kizgin, H. (2018). Prevention of cybercrimes in smart cities of India: From a citizen's perspective. Information Technology \& People, ITP-05-2018-0251. https://doi.org/10.1108/ITP-05-2018-0251.

Chatterjee, S., Kar, A. K., \& Gupta, M. P. (2018a). Alignment of IT authority and citizens of proposed smart cities in India: System security and privacy perspective. Global Journal of Flexible Systems Management, 19(1), 95-107. https://doi.org/10.1007/ s40171-017-0173-5.

Chatterjee, S., Kar, A. K., \& Gupta, M. P. (2018b). Success of IoT in smart cities of India: An empirical analysis. Government Information Quarterly, 35(3), 349-361. https://doi.org/10.1016/J.GIQ.2018.05.002.

Dwivedi, Y. K., Weerakkody, V., \& Janssen, M. (2012). Moving towards maturity: Challenges to successful e-government implementation and diffusion. ACM SIGMIS Database, 42(4), 11. https://doi.org/ $10.1145 / 2096140.2096142$.

Gil-Garcia, J. R., Zhang, J., \& Puron-Cid, G. (2016). Conceptualizing smartness in government: An integrative and multi-dimensional view. Government Information Quarterly, 33(3), 524-534.

Gupta, P., Chauhan, S., \& Jaiswal, M. P. (2019a). Classification of smart city research - a descriptive literature review and future research agenda. Information Systems Frontiers, 21(3). https://doi.org/10. 1007/s10796-019-09911-3.

Gupta, S., Drave, V. A., Bag, S., \& Luo, Z. (2019b). Leveraging smart supply chain and information system agility for supply chain flexibility. Information Systems Frontiers, 21(3). https://doi.org/10.1007/ s10796-019-09901-5.

Hollands, R. G. (2008). Will the real smart city please stand up? Intelligent, progressive or entrepreneurial? City, 12(3), 303-320.

Janssen, M., \& Helbig, N. (2018). Innovating and changing the policy-cycle: Policy-makers be prepared! Government Information Quarterly, 35(4), S99-S105. https://doi.org/10.1016/J.GIQ.2015.11.009.

Janssen, M., \& Kuk, G. (2016). The challenges and limits of big data algorithms in technocratic governance. Government Information Quarterly, 33(3), 371-377. https://doi.org/10.1016/j.giq.2016.08.011.

Janssen, M., Matheus, R., \& Zuiderwijk, A. (2015). Big and open linked data (BOLD) to create smart cities and citizens: Insights from smart energy and mobility cases. In E. Tambouris, M. Janssen, H. J. Scholl, M. A. Wimmer, K. Tarabanis, M. Gascó, B. Klievink, I. Lindgren, \& P. Parycek (Eds.), Electronic Government (Vol. 9248, pp. 79-90): Springer International Publishing.

Ju, J., Liu, L., \& Feng, Y. (2019). Design of an O2O citizen participation ecosystem for sustainable governance. Information Systems Frontiers, 21(3). https://doi.org/10.1007/s10796-019-09910-4.

Kankanhalli, A., Charalabidis, Y., \& Mellouli, S. (2019). IoT and AI for smart government: A research agenda. Government Information Quarterly, 36(2), 304-309.

Liu, P., \& Peng, Z. (2014). China's smart city pilots: A progress report. Computer, 47(10), 72-81. https://doi.org/10.1109/MC.2013.149.

Matheus, R., Janssen, M., \& Maheshwari, D. (2018). Data science empowering the public: Data-driven dashboards for transparent and accountable decision-making in smart cities. Government Information Quarterly. https://doi.org/10.1016/j.giq.2018.01.006.

Rahman, M., Bose, S., Babu, M. M., Dey, B. L., Roy, S. K., \& Binsardi, B. (2019). Value co-creation as a dialectical process: Study in Bangladesh 
and Indian Province of West Bengal. Information Systems Frontiers, 21(3). https://doi.org/10.1007/s10796-019-09902-4.

Rana, N. P., Luthra, S., Mangla, S. K., Islam, R., Roderick, S., \& Dwivedi, Y. K. (2018). Barriers to the development of smart cities in Indian context. Information Systems Frontiers, 21(3). https://doi. org/10.1007/s10796-018-9873-4.

Tammpuu, P., \& Masso, A. (2019). Transnational digital identity as an instrument for global digital citizenship: The case of Estonian eresidency. Information Systems Frontiers, 21(3). https://doi.org/10. 1007/s10796-019-09908-y.

Villa, N. (2015). Digital Nations: accelerating progress, delivering results. Manchester, UK, CISCO, https://www.cisco.com/c/dam/assets/ global/EMEAR/assets/internet-of-everything-ioe/Digital_ Transformation countries.pdf. Accessed 01 Mar 2019.

Wang, Y., Jin, L., \& Mao, H. (2019). Farmer cooperatives' intention to adopt agricultural information technology-Mediating effects of attitudes. Information Systems Frontiers, 21(3). https://doi.org/10. 1007/s10796-019-09909-x.

Publisher's Note Springer Nature remains neutral with regard to jurisdictional claims in published maps and institutional affiliations.

\begin{abstract}
Arpan Kumar Kar is Associate Professor in the Information Systems area at the Department of Management Studies, Indian Institute of Technology Delhi, India. His research interests are in the domain of data science, digital transformation, machine learning, social media, and ICT-based public policy. He has published over a hundred articles in in Elsevier, IEEE, Springer, ACM, Taylor \& Francis, and Emerald. He is Managing Editor of Global Journal of e-Business \& Knowledge Management and Associate Editor of Global Journal of Flexible Systems Management. Previously, Kar worked for the Indian Institute of Management Rohtak, the IBM India Research Laboratory, and Cognizant Business Consulting. He has also managed multiple major research and consulting projects by private and public organizations for the Government of India. Over the years, Kar has received numerous awards and recognitions for his contribuions in research from several organisations including the Association of Indian Management Schools, International Federation for Information Processing, Elsevier, Tata Consultancy Services, Project Management Institute, IIT Delhi and IIM Rohtak.
\end{abstract}

Vigneswara llavarasan is Associate Professor at the Department of Management Studies, Indian Institute of Technology Delhi. He researches and teaches about the production and consumption of Information and Communication Technologies (ICTs) with a special focus on India. His specific research interests are Information and Communication Technologies \& Development (ICTD); the Indian IT industry; and social media. He is an active contributor to international journals and conferences. He has been a Visiting Research Fellow at United Nations University, School of Computing and Society (Macau). Ilavarasan is also a recipient of the Outstanding Young Faculty Fellowship Award at IIT Delhi and the Prof. M.N. Srinivas Memorial Prize of the Indian Sociological Society. He is also a Research Fellow at LIRNEasia, a regional ICT policy and regulatory think-tank. He has received large research grants from IDRC (Canada), the Government of India, Oxford Analytica (UK), IPTS (European Commission), and IdeaCorp (The Philippines).
M. P. Gupta is Professor of Information Systems at the Department of Management Studies, Indian Institute of Technology Delhi. Known for his pioneering work in the area of e-governance, he has allocated significant resources to develop case studies, tools and frameworks in text books to promote e-governance. This investment has resulted in 24 doctoral theses, 17 sponsored mega-projects, four co-authored / edited books and over 200 research papers. Gupta has closely followed the Government of India (GoI) National Plan on E-governance, which developed subsequently into the umbrella programme 'Digital India'. His studies have contributed to these programs in general and 'Cyber Security Policy of India' in particular. His recent interest lies in exploring some of the issues of smart cities. Currently, he is also steering a European Union funded project (Horizon 2020) involving setting up cluster-to-cluster partnerships between India and the EU for the convergence of the Future of Internet \& Digital Media (FI-MEDIA).

Marijn Janssen is Professor in ICT \& Governance and chair of the Information and Communication Technology section of the Technology, Policy and Management Faculty of Delft University of Technology. He is also an honorary visiting professor at Bradford University, UK. His research interests are in the field of orchestration, shared services and algorithms in open and big data and infrastructures. $\mathrm{He}$ is co-Editor-in-Chief of Government Information Quarterly (GIQ), and associate editor of the International Journal of E-Business Research (IJEBR), International Journal of Electronic Government Research (IJEGR), and Decision Support Systems (DSS). Janssen is on the editorial board of Information Systems Frontiers (ISF), Transforming Government: People, Process \& Policy (TGPPP) and Information Polity (IP). He is also conference chair of the IFIP EGOV series and is chairing mini-tracks at the dg.o, ICEGOV and AMCIS conferences. He was ranked as one of the leading e-government researchers in surveys in 2009, 2014 and 2016, and has published over 400 refereed publications. He was nominated in 2018 by Apolitical as one of the 100 most influential people in the Digital Government https://apolitical.co/lists/digitalgovernment-world100. For more information, see www.tbm.tudelft.nl/ marijnj.

Ravi Kothari is Professor of Computer Science at Ashoka University. His expertise is in machine learning, neural networks, stream processing, and other data-driven technologies. His current area of research focuses on creative machines, fairness and transparency aspects of machine learning, and learning from streaming data. He has over hundred publications and has been issued 30 patents in these areas. Previously Kothari worked for 15 years at IBM, where he was last an IBM Distinguished Engineer and Chief Scientist of IBM Research, India. For about ten years, he also was Associate Professor and Director of the Artificial Neural Systems Laboratory at the University of Cincinnati (USA) achieving tenure. Over the years, Kothari has served as an Associate Editor of the IEEE Transactions on Neural Networks, IEEE Transactions on Knowledge and Data Engineering, and Pattern Analysis and Applications. He has also been the General Chair and had other organising roles at multiple conferences. Further, Kothari has received several recognitions including being an IEEE Distinguished Visitor, a member of the IBM Academy of Technology and the IBM Industry Academy. He was a recipient of the Best of IBM award (IBM's highest individual award) and the IBM Gerstner Award (IBM's highest team award). Kothari is a fellow of the Indian National Academy of Engineering. 